\title{
Planning for open space and recreation
}

\author{
A.J. Veal \\ Business School \\ University of Technology Sydney
}

Published : Veal, A.J. (2020) Planning for open space and recreation. Australian Planner, online: http://dx.doi.org/10.1080/07293682.2020.1739091.

\section{Introduction}

Planning for open space and recreation in Australia was traditionally based on populationratio standards, which specify the area of open space required per 1000 population, or areapercentage standards, which specify the percentage of land which should be reserved for open space. For some decades such standards have been subject to criticism on a number of grounds. Consequently, open space and recreation planners have been faced with the challenge of developing alternatives to replace the standards approach. While a number of possibilities have been put forward, two main alternatives have emerged in Australia: the catchment access based standard and demand-based planning.

In this paper these two approaches are evaluated and found wanting and a third alternative emerging from national and state-level planning is presented. Before presenting this analysis, however, three topics are briefly discussed: the question of scope; the problems with traditional standards; and the continued adherence to traditional standards by some organisations.

\section{Scope}

The focus of this paper is 'open space and recreation'. 'Open space' in this context refers to land which is accessible to the public for recreational purposes. 'Recreation' takes on a number of meanings depending on the context in which the term is being used (Veal, Darcy and Lynch 2013, 19). In the local planning context this typically includes sport and other forms of formal and informal physical recreation. However, a number of activities, such as swimming, basketball and netball, can take place in both indoor and outdoor spaces, so indoor sport/recreation facilities are often included within the scope of planning for recreation and this practice is followed here. Table 1 lists the range of types of recreational/open space facilities included, with examples of activities accommodated.

Table 1 Types of recreational facility and associated recreational activity

\begin{tabular}{|l|l|}
\hline Facility types & Examples of recreational activity accommodated \\
Playing fields & Team sports, e.g. football (various codes), cricket, hockey \\
Outdoor courts & Netball, basketball, tennis \\
Linear: paths, trails & Walking, running/jogging, cycling \\
Specialist outdoors & Athletics, bowls, golf, motor sports, roller sport \\
Water-based outdoor & Fishing, sailing, ocean/lake/river swimming, surfing \\
Natural areas & Bushwalking, rock-climbing \\
Urban parks (informal areas) & Informal recreation, children's play, walking, cycling \\
Indoor/outdoor pools & Swimming, diving, water polo \\
Large sports halls & Indoor: basketball, netball, tennis, cricket, soccer, training; badminton \\
Small halls & Fitness, martial arts, boxing, yoga \\
Indoor specialist & Squash, ten-pin bowling, weight-training/fitness \\
\hline
\end{tabular}




\section{The problems with standards}

Traditional population-ratio and area-percentage standards for open space provision have long been criticised on grounds of their 'one-size-fits-all' nature and their general lack of evidentiary basis (e.g., Gray and Cullen 1976, 30-31; Marriott 1980a, 1980b; Gold 1980, 180-81; Jeavons 2000; Taylor 2010, 374-76; Byrne and Sipe 2010, 21; Veal, 2017 158-60). A particular problem with the standards used in Australia has been that, while it has generally been claimed that they were adapted from British and American origins, documentation of this adaptation process is lacking (Veal 2013). The origins and rational basis for these traditionally used standards are therefore shrouded in mystery.

A particular failing of the traditional standards approach which is becoming particularly relevant in Australian cities, is the failure to take account of variations in residential density. This was identified 70 years ago, in Brown and Sherrard's (1951, 149-50) classic planning text. Table 2 illustrates the problem. It examines the implications of the two forms of the traditional standard for a range of residential densities. Under the population-ratio standard, the quantum of open space for a population of 1000 remains the same (column C) regardless of density. However, the percentage of land allocated to open space increases (column D) until, at a density of 353 persons/ha, the absurd proposition emerges in which $100 \%$ of the land area would be allocated to open space. Under the area-percentage standard, as density increases, the percentage of land allocated to open space remains constant (column E) but the quantum of open space falls (column F), so that per capita open space falls. Of course, in practice standards are not applied so rigidly, but available guidelines are unclear as to the process by which they should be modified to deal with the density issue.

Table 2. Application of traditional open space standards at varying residential densities

\begin{tabular}{|c|c|c|c|c|c|}
\hline \multirow{2}{*}{$\begin{array}{l}\text { A. Density, } \\
\text { persons } \\
\text { per ha. }\end{array}$} & \multirow{2}{*}{$\begin{array}{c}\text { B. Total } \\
\text { residential } \\
\text { land for } 1000 \\
\text { persons } \\
(1000 / \mathrm{A})\end{array}$} & \multicolumn{2}{|c|}{ Population-ratio standard } & \multicolumn{2}{|c|}{ Area-percentage standard } \\
\hline & & $\begin{array}{l}\text { C. Open space: } \\
\text { @ 2.8ha./ } 1000 \\
\text { population* }\end{array}$ & $\begin{array}{l}\text { D. Implications: } \\
\text { open space as \% } \\
\text { of res. land } \\
\left(C^{*} 100 / B\right)\end{array}$ & $\begin{array}{l}\text { E. Open space as } \\
\% \text { of residential } \\
\text { land area }\end{array}$ & $\begin{array}{l}\text { F. Implications: } \\
\text { area of land for } \\
\text { open space, ha. } \\
(10 \% \text { of } B)\end{array}$ \\
\hline 35 & 28.6 ha. & $2.8 \mathrm{ha}$. & $10.0 \%$ & $10 \%$ & 2.86 \\
\hline 50 & 20.0 ha. & 2.8 ha. & $14.1 \%$ & $10 \%$ & 2.0 \\
\hline 100 & 10.0 ha. & 2.8 ha. & $28.3 \%$ & $10 \%$ & 1.0 \\
\hline 200 & 5.0 ha. & 2.8 ha. & $56.6 \%$ & $10 \%$ & 0.5 \\
\hline 353.3 & $2.8 \mathrm{ha}$. & 2.8 ha. & $100.0 \%$ & $10 \%$ & 0.28 \\
\hline
\end{tabular}

( ${ }^{*}$ Traditional NSW open space standard)

\section{Continued adherence to the standards approach}

Despite the body of opinion on their limitations, the standards approach continues to be advocated by some. Examples include guidelines published by: the WA Department of Sport and Recreation (2007); consultants Australian Social and Recreation Research (2008) for a consortium of Victorian local councils; the Victorian Growth Areas Authority (2009); and Parks and Leisure Australia, WA (2012). Since these standards-based guidelines have typically been designed for specific metropolitan growth areas, it might be argued that they escape the one-size-fits-all criticism if such areas have a known socio-demographic profile and the standards are based on the consequent recreational demand likely to be generated from such communities. However, the published reports provide no indication of such a justification. In fact, no basis or sources for any of the standards are presented. One of the 
documents indicates that the standards were based on 'extensive research conducted across Australia, New Zealand, USA, Canada and the UK and workshopped by industry professionals' (Parks and Leisure Australia, WA 2012, 3). Another declares that demand modelling using Victorian participation data shows that 'a minimum of 2.0 ha. of sports grounds per 1000 population is required to meet current participation levels and demand for sport' (Australian Social and Recreation Research 2008, 8-9). But in neither case are the details of the research presented or sources indicated.

\section{Alternatives to traditional standards}

\section{The catchment access based standard}

The term catchment access based standard (CABS) was coined in the open space/recreation planning guidelines published in 2010 by the New South Wales Department of Planning $(2010,28)$. It was intended to be a move away from the traditional 'simple fixed, quantitative standard', which was seen as 'irrelevant' (p. 27). Without using the particular term, the CABS had in fact been endorsed as early as 1995 in the federal government-sponsored neighbourhood planning guidelines: the Australian Model Code for Residential Development (AMCORD) (Commonwealth of Australia/ Department of Health, Housing and Community Services, 1995).

The CABS involves specification of minimum sizes for various categories of open space, together with maximum distances which residents need to travel to access them, the latter specifying a catchment radius. Since neither the AMCORD or the NSW Department of Planning report provided any evidential basis or sources for the particular specifications provided, they, in effect, continued the Australian tradition of offering planning guidelines with unspecified origins.

Although the CABS specifications are presented as a 'move away from a standards-based approach', they can be shown to be equivalent to a population-ratio standard. This is not indicated in the AMCORD or NSW documents but can be demonstrated as follows. Table 3 presents the three categories of open space referred to in the AMCORD report and their corresponding specifications (columns $\mathrm{R}$ and $\mathrm{A}$ ). The specified catchment radii of the parks (column R) determine the sizes of the residential areas they serve (column B). Thus, the district park serves an area of 1256 ha., while the smallest category, the local park, serves an area of 28.3 ha. It can be seen, therefore, that a fully-provided district would contain one district park, 44 'local' parks and 16 'large local' parks (column C). The total area of the 61 parks specified for a district is therefore $18 \mathrm{ha}$, which can be expressed in traditional areapercentage format as $1.4 \%$ of the land area (column D).

Table 3. 'Catchment access based standard' specifications: implied park area for a district

\begin{tabular}{|c|c|c|c|c|c|}
\hline \multirow{2}{*}{\begin{tabular}{|l|} 
\\
$\begin{array}{l}\text { AMCORD park } \\
\text { types }\end{array}$ \\
\end{tabular}} & \multicolumn{2}{|c|}{ AMCORD specifications } & \multirow{2}{*}{\begin{tabular}{|c|}
$\begin{array}{c}\text { Residential area } \\
\text { served by park }\end{array}$ \\
B \\
$\left(\pi R^{2}\right)$ \\
ha.
\end{tabular}} & \multicolumn{2}{|c|}{ District level calculations } \\
\hline & $\begin{array}{l}\mathrm{R} \\
\text { Catchment } \\
\text { radius, m. }\end{array}$ & \begin{tabular}{|c|} 
A \\
Individual \\
park area, ha.
\end{tabular} & & $\begin{array}{c}\text { C } \\
\text { Number of parks } \\
(1256 / \mathrm{B})\end{array}$ & $\begin{array}{c}\text { D } \\
\text { Total park area, } \\
\text { ha. }(C \times A)\end{array}$ \\
\hline Local park & 300 & 0.2 & 28.3 & 44 & 9 \\
\hline Large local park & 500 & 0.4 & 78.5 & 16 & 6 \\
\hline District park & 2000 & 3.0 & 1256.0 & 1 & 3 \\
\hline \multicolumn{5}{|l|}{ Total park area: } & 18 ha. \\
\hline \multicolumn{5}{|c|}{ Park area as $\%$ of district residential area $(100 * 18 / 1256)$ : } & $1.4 \%$ \\
\hline
\end{tabular}


Table 4 shows how this can be presented in population-ratio format. For a district of $1256 \mathrm{ha}$, if the residential density is known (column E), the population size can be calculated (column F). The 18 ha of park space therefore implies a population-ratio standard for each density level (column G). This ranges from 0.41 ha/1000 in low-density areas to 0.15 ha/1000 in high density areas.

Table 4. District of 1256 ha: park area of 18 ha (from Table 3) expressed as population-ratio standard, by density level

\begin{tabular}{|l|c|c|c|}
\hline Density level & $\begin{array}{c}\text { E } \\
\text { Density, persons/ha. }\end{array}$ & $\begin{array}{c}\mathbf{F} \\
\text { District population } \\
(\text { A x District area (1256ha) })\end{array}$ & $\begin{array}{c}\text { G } \\
\text { Equivalent population-ratio standard } \\
(18 \text { ha/B/1000) }\end{array}$ \\
\hline Low & 35 & 43,960 & 0.41 ha. $/ 1000$ \\
Medium & 50 & 62,800 & 0.29 ha. $/ 1000$ \\
High & 100 & 125,600 & 0.15 ha. $/ 1000$ \\
\hline
\end{tabular}

Thus the CABS is shown to be not an alternative to traditional standards but itself a version of them. Furthermore, the implied standards are radically lower than the $2.8 \mathrm{ha} / 1000$ and 5$10 \%$ traditionally used in Australia. It could be argued that, because of the density dimension, this is no longer a 'one-size-fits-all' approach, but the variation by density is not spelled out in the AMCORD or the NSW report, so it is not clear that the authors were aware of this feature.

The CABS specifications provided in the NSW 2010 guidelines are described as 'default standards', which are presented as the 'starting point' from which local councils should work (NSW Department of Planning 2010, 28). The default standard should be modified by 'local needs analysis" , involving consideration of such factors as: the demographic profile of the population; transport/accessibility; and availability of regional open space. While a case study example is provided, details of how the analysis was carried out to produce the modification shown are not indicated. Regardless of how the modifications to the default standard are undertaken, a fundamental question arises. If there are modifying factors which are sufficiently significant that they justify a level of provision different to the 'default standard', then why are these factors not used to determine the required level of provision in the first place?

\section{Demand-based planning approach: published guidelines}

Open space/planning guidelines invariably refer to a number of basic tasks, such as compiling an inventory of existing physical assets and organisations and reviewing relevant existing plans of council and other agencies. The analysis below is not concerned with these, albeit vital, tasks but with the distinctive core demand/participation-related processes which underlie decisions regarding facility/service requirements. Four examples of Australian guidelines recommending the use of demand-based planning are discussed here: two from New South Wales and one each from Tasmania and Victoria.

\footnotetext{
${ }^{1}$ In a number of guideline documents, the term 'need' is used, rather than 'demand' - both terms present complex definitional issues which cannot be pursued here (but see, Veal 2017, Ch. 3 'Wants, needs, demand, benefits and participation', pp. 44-72).
} 
In New South Wales, the intention of the state government to move away from reliance on traditional standards dates from at least 1984 (NSW Department of Environment and Planning 1984, 4) but was most clearly stated in the Department of Planning's 1992 guidelines, as follows:

The underlying philosophy of the department in these guidelines is that open space is a means to an end - it is there because people need it. It follows that recreation demand should drive the process, not open space supply through the implementation of standards. This area of planning is dealing firstly with people and their use of space, not vice versa. (NSW Department of Planning 1992, 19)

The guidelines set out an approach to demand-based planning characterised by extensive guidance on data collection, but little advice on how the collected data should be analysed. The details of the guidelines need not detain us here, since they were superseded in 2010. However, two features should be mentioned. Fist, a distinction is made between planning for three types of area: developed areas, where 'the open space system is already largely in place'; new release areas, where 'there is no existing open space system or community'; and infill areas, which 'combine the characteristics' of the other two (p. 3). A new release area would therefore lack one of the key data sources, community consultation/surveys. This could be overcome by 'comparing it with a developed area with similar topography, demography and urban form' (NSW Department of Planning 1992, 16). The issue is discussed further at the end of this article. Second, is the issue of demand/ participation outcomes of the planning process, or its 'performance indicators'. In these guidelines, 15 possible indicators are briefly listed, but the volume of recreation activity taking place in the facilities developed as a result of the plan is not one of them (p. 23). This issue is also discussed further below.

The latest NSW 2010 guidelines are, as noted above, focussed primarily on the CABS approach, but they also suggest that a demand-based approach might be used, since advice is presented on the collection of data to 'understand demand and needs' (NSW Department of Planning 2010, 20). The relationship between the two approaches is, however, not indicated. The 1992 distinction between new release and other types of area is not mentioned. It is indicated that, for the demand-based approach, data should be assembled on: state and national trends in participation in sporting and recreational activities; demographic/cultural characteristics of potential users; local participation, facility and program use; and 'conservation values and landscape qualities of candidate areas' (p. 21). However, no guidance is provided on how to analyse the data.

The section of the guidelines discussing the contents of a planning report includes 'comparison of demand and supply' (p. 40) but there is no indication of the relationship between this and the decision-making process on open space/facility requirements. In regard to outcomes of the planning process, the section on 'monitoring and review' includes 'periodic surveys' to determine, inter alia, 'the number of people using the land at various times by activity type' (p. 45), but again there are no details on how such data should be used to evaluate performance - for example by comparing them with the level of demand originally planned for. 
The guidelines published by Sport and Recreation Tasmania in 2010 were compiled by Dr Ken Marriott, one of the most experienced recreation planning consultants in Australia. The title of the guidelines report, Planning for the Provision of Leisure and Recreation in Australia, suggests that its intended audience is not limited to Tasmania. The key recommended approach to planning is a combination of community consultation and demand assessment.

Community consultation involves such techniques as focus groups, surveys, public meetings and community panels. These are to gather information from residents on 'issues likely to affect them', which 'extends democratic principles' (Sport and Recreation Tasmania 2010, 76). In regard to possible future demand aspirations, it also involves identification of the public's 'interests and preferences for types of activities' (p. 82) and the views of representative organisations on 'priorities for action' (p. 84). These guidelines do address the issue of data analysis (p. 85), with advice given in broad terms as to how to undertake 'evaluation ... of the information which has been collected', with recognition that 'there could be incompatibilities between the 'needs, aspirations and priorities' discovered in the consultative research and the 'goals, mission statements, principles and objectives' of the council. A series of 14 questions is presented to interrogate survey and other collected data (pp. 118-9). However, the report stops short of providing step-by-step instructions as to how the answers to these question should be analysed to provide an overall picture of the recreation demand which is to be met.

The report recognises the unique characteristics of greenfield sites (or 'new release areas' to use the NSW 1992 guidelines term), observing that they have "no community to consult and no existing provision to review and evaluate', so 'a number of the planning strategies ... covered in this manual cannot be applied' (p. 104). The solution in regard to demand determination is to refer to demographics and provision/activity patterns in 'nearby residential areas' (pp. 105-6) or benchmarking with 'other established communities' (p. 108). This issue is discussed further at the end of this article.

Monitoring and review are briefly discussed (p. 123), but its focus is on taking account of social change over time rather than evaluating the outcomes of the initial planning exercise.

Parks and Leisure Australia (Victoria branch), 2013

A set of guidelines produced by the Victorian branch of the professional organisation, Parks and Leisure Australia (2013) includes a demand-based component under the heading: 'Identify the needs - future demand for open space'. The full extent of the guidance provided for this task is a 12-point, one-page 'checklist', covering the following topics:

1. The expressed need/demand identified by key stakeholders in consultation phase.

2. Consideration of private backyard sizes, private/communal open space in high density areas.

3. Recorded, anecdotal and observed demand for public open space by residents and visitors.

4. Types of open spaces and functions that are the subject of such demand.

5. Perceived attitudes about open space identified in previous community engagement projects.

6. Existing participation trends and how these compare to national, state and local trends

7. Locational and size requirements of open space. 
8. Identify physical, financial, social, cultural constraints to using public open space.

9. Analysis of quality, size and capabilities of existing open space.

10. Hierarchy the open space network: catchments, location, distribution.

11 . The connectivity of the open space network.

12. Benchmarking of provision re. population size, demographics, barriers to access, local needs and trends in demand and usage and six other variables (pp. 37-38).

Again, there is no indication as to how this information should be collated and analysed to produce a plan.

\section{Demand-based guidelines summary}

A common feature of the four sets of guidelines on demand-based planning is that they indicate that the approach involves a considerable amount of data collection, but they provide incomplete or no guidance on how the data should be analysed as part of a decision-making process. This, of itself, does not necessarily invalidate the approach, since more detailed advice on the procedures used in practice could be compiled. The core logic of the approach, broadly stated, is that the plan for facility and service provision is based on estimated currently unmet or future growth in demand for recreation participation based on general societal trends, local demographic trends and the views of community members and organisations concerning participation constraints and aspirations. The level of recreational participation to be catered for by new or enhanced facilities or programs is therefore a response to these trends, constraints and aspirations. In practice, of course, demand/ participation levels and patterns are also partly shaped by the actions of leisure providers themselves.

The essence of this approach is summarised in Figure 1. The status quo is represented by current demand/participation (1) taking place in existing facilities/programs (2). A wide range of data (3) derived from community individuals and organisations and other sources is collected and analysed (4) to indicate required new and/or enhanced facilities/programs (6). An estimate can be made of total additional demand to be met (5) but this is not presented in most applications. Recreation demand/participation is made up of participation in a range of activities which may or may not be aggregated to a single figure in a typical plan. One approach is to assemble demand/participation data into facility-linked activity groups as indicated in Table 1, to aid the process of converting demand estimates into facility/service requirements. Demand/participation figures may also be subdivided by socio-demographic factors such as age or gender, typically to connect with a local council's broader social policy priorities. The resultant usage of the new/enhanced facilities/programs (7) and resultant new overall demand/participation level (8) are evaluated (9), particularly in relation to the additional demand which was planned for. The last three components constitute an assessment of the success of the planning exercise but are typically underplayed in the demand-based planning guidelines. From a limited land-use planning point of view, the exercise is complete at step 6. Few, if any, local councils conduct follow-up recreation demand/participation surveys to assess the outcomes of recreation planning exercises.

The responsive demand model contrasts with the more proactive stance recently adopted at national level and in some states, which have potential implications for local planning. This is discussed in the next section. 


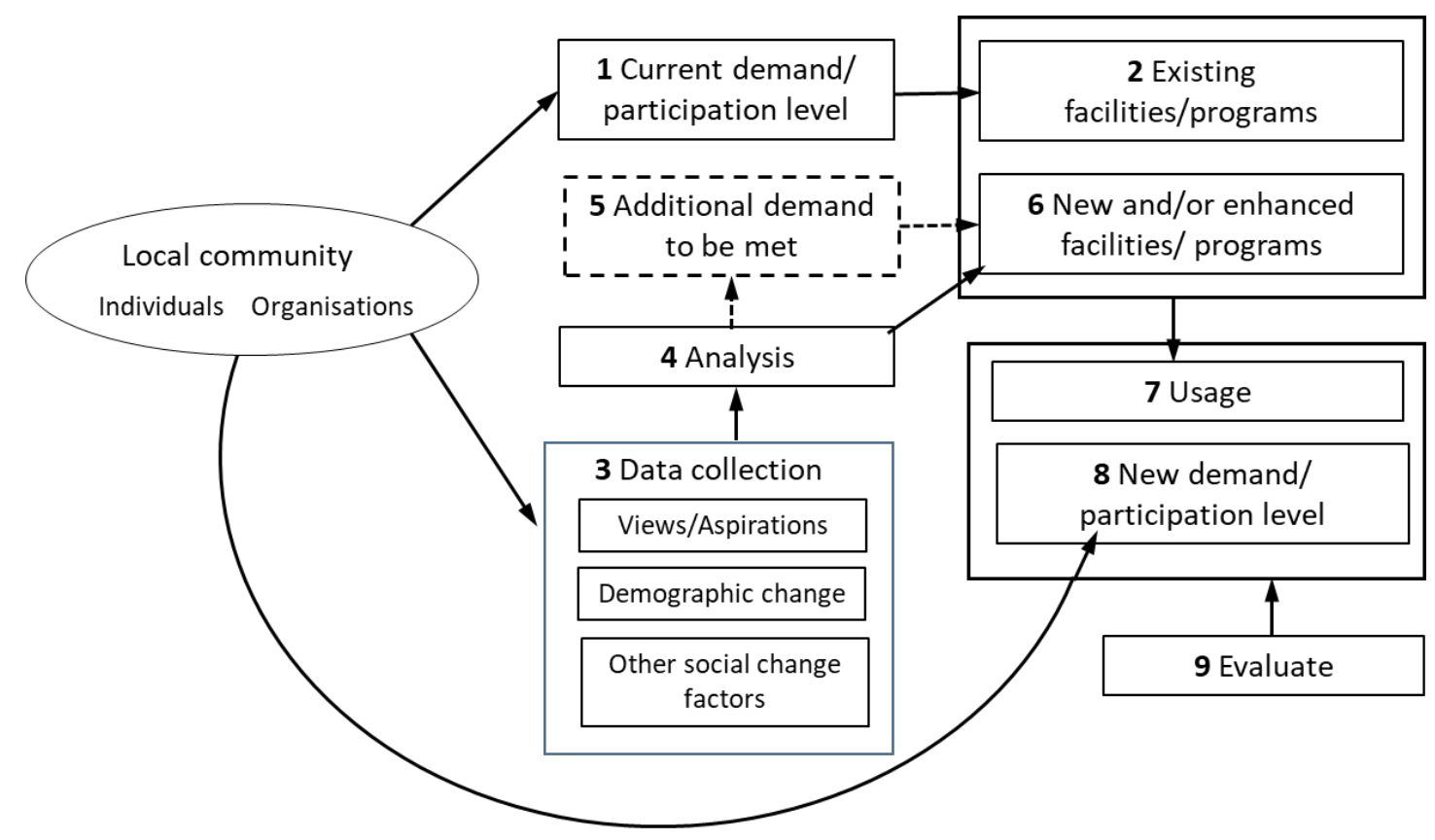

Figure 1. Local demand-based planning model

\section{National policy for sport/recreation participation}

The policy responsibilities of the Australian federal government in regard to open space and recreation do not fully coincide with those of local government, but they do have significant overlaps. They include recreation, but not open space. The federal government's designated minister, main delivery agency (Sport Australia) and policy statements are focussed on sport. While this includes élite national representative sport, it also includes grassroots sports participation. Furthermore, this is interpreted quite broadly, as the recent national plan, Sport 2030, indicates:

When the Australian Government talks about 'sport' and sport policy, it will now talk about a broad range of physical activities including informal, unstructured activity such as walking, riding, swimming and running as well as traditional, structured sport. (Australian Government 2018, 6)

This inclusive definition of 'sport' coincides with most of the range of activities broadly referred to at the local government level as 'recreation' (see Table 1).

The federal government's policy stance is proactive in regard to participation. This is encapsulated in the statement in Sport 2030 that: 'fewer Australians are playing sport and engaging in physical activity - this is a trend we need to reverse' (Australian Government 2018,2 ). This is based on the finding that only $30 \%$ of adults and $19 \%$ of children (p. 16) meet the health-related minimum physical activity guidelines (Australian Institute of Health and Welfare 2018; World Health Organization 2010). The approach is therefore not based on the proposition that a certain amount of current and/or future demand exists and must be discovered and catered for. Rather, the view is taken that the current level of demand/ participation is too low and must therefore be boosted.

While earlier national plans had presented a similar policy commitment to increase participation, Sport 2030 breaks relatively new ground for Australia by quantifying the intent 
and adding a time line. It announced a 'long-term target' to: 'Reduce inactivity amongst Australians by $15 \%$ by 2030 ' (Australian Government 2018, 4, 19). In its most recent corporate plans, Sport Australia, the main vehicle for implementing the national plan, has converted the long-term target into specific annual target numbers of additional participants (Sport Australia 2019, 20). Typical target increases in the number of active adults are 200,000 a year, a very modest $1 \%$ of the adult population. Similar targets are presented for children (under 15).

This approach can be seen as only relatively new since there have been examples of quantitative target-setting by governments in the past. In the United Kingdom, in the lead-up to hosting the 2012 London Olympics, the government set a target of increasing the number of people playing sport by two million between 2006 and 2012 (Houlihan 2011, 21), although this was later reduced to a less ambitious one million (Department for Culture, Media and Sport 2008, 8). In 2002, the then Australian Sports Commission announced a target of increasing the number of sports participants in Australia by 2005 (Australian Sports Commission 2002,6). This policy, was implemented by agreements with national sporting organisation (NSOs): the Targeted Sports Participation Growth Program (TSPGP). It seems to have been a partial success (Australian Sports Commission 2006, 52), but was not continued in subsequent strategic plans.

A number of state governments have also set participation targets, including:

- South Australia, which aimed to 'exceed the Australian average for participation in sport and physical activity' by 2014 (South Australian Government 2007, 19); and 'increase the proportion of SA adults participating in sport or physical recreation at least once per week to $50 \%$ ' by 2020 (SA Government 2016, 1).

- New South Wales which:

$\circ$ in 2010, aimed at a 10\% increase in participation in 'sporting, recreational, arts and cultural activities' by 2016 (NSW Government 2010, 51); and

$\circ$ in 2017 , set a target of $65 \%$ of adults engaging in regular physical activity by 2025 ; and 30\% of children engaging in regular physical activity by 2020 (NSW Office of Sport 2017, 12).

- Victoria, which aimed at a $20 \%$ increase in the number of adolescents and a $10 \%$ increase in the number of adults doing 'sufficient physical activity' by 2025 (State of Victoria $2017,25)$.

As with the local demand-based planning model, the national/state model can be represented visually, as in Figure 2. It involves current participation levels (1) being analysed (2) by reference to health-related physical activity guidelines (3), leading to the setting of participation targets (4). Implementation is delegated to Sport Australia and is undertaken via direct promotion (5), such as the most recent 'Move It AUS' initiative (Jones 2018)) ${ }^{2}$, and programs conducted by NSOs (6), such as the TSBGP mentioned above. The potential role of the states/territories (6a) is discussed below. The activity of Sport Australia and the NSOs results in an increased level of participation (7), which can be compared with the target to assess the overall performance of the planning exercise (8). As with the local planning model, the single 'current demand/participation level' is made up of a number of components. At national level, these include the activities for which individual NSOs are responsible, and there is a division between adults and children.

\footnotetext{
${ }^{2}$ Referred to on the Sport Australia website as 'Find your 30': see www.sportaus.gov.au/findyour30.
} 


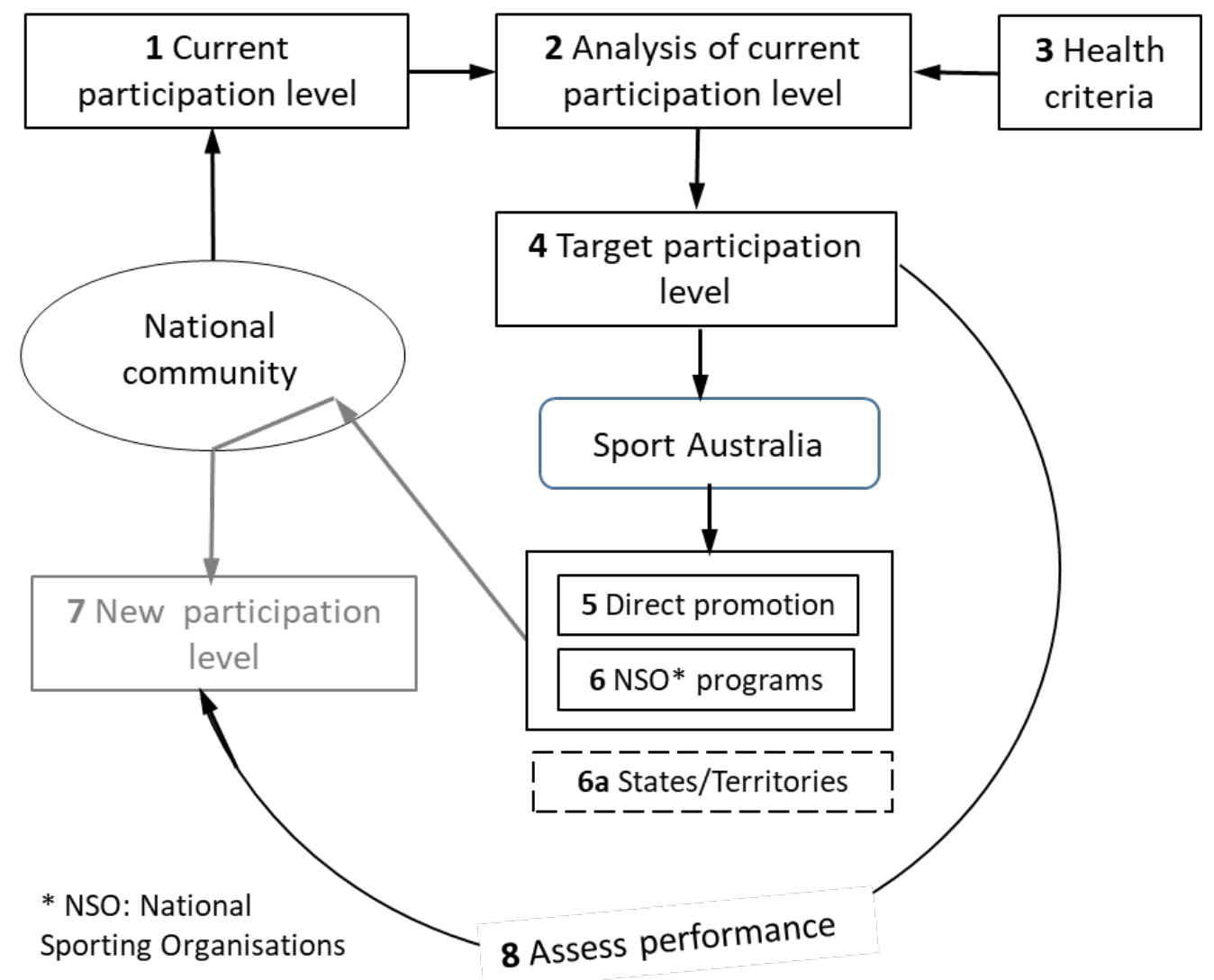

\section{Figure 2. National sport/recreation planning model}

The focus in this model is not on a level of anticipated demand emerging from social change and expressed aspirations, but a target participation level set by the planning agency. Therefore, to distinguish it from the demand-based approaches discussed above, it might be termed a participation-based model.

This participation-based model did not spring from nowhere. It can be seen as an indication that the sport sector is adapting to the evidence-based policymaking and accountability regime of federal government (Productivity Commission 2009; Australian National Audit Office 2018). As demonstrated by its corporate plans (e.g., Sport Australia 2019) and budget documents (e.g., Australian Government 2019), Sport Australia, as a government-funded statutory body, is required to present measurable 'performance criteria' and 'outcomes' with annual indicators and targets over a four-year budget cycle. It follows practice in other areas of public policy, such as education and health, which have come to focus on seeking to improve in outcomes, rather than merely accounting for inputs. The outcome in the sport sector is sport/recreation participation. To ensure a continuous flow of data for this purposes, Sport Australia conducts the AusPlay participation survey, which has an annual sample of 20,000 respondents (Sport Australia, bi-annual).

There is a relationship between this national-level activity and local planning for sport/ recreation. Clearly, the communities served by individual local councils collectively constitute the national community served by the federal government. Furthermore, sport/ recreation participation activity in Australia, as measured by the AusPlay survey, is substantially dependent on formal and informal facilities provided by local councils. Even 
club facilities are often leased from, and/or subsidised by, councils. Available data suggests that local government expenditure on sport/recreation is four times that of the federal government and double that of the states and territories (Veal et al. 2013, 171). Arguably then, the 15\% increase in national demand/participation, as targeted in Sport 2030, could only be achieved if there was a corresponding response from the providers of sport/recreation facilities throughout the country, that is, local councils.

It might therefore be expected that the national policy for sport/recreation development would be linked in some way with local level policy and planning processes, perhaps via the states/ territories. In 2011, the National Sport and Active Recreation Policy Framework (NSARPF) (Australian Governments 2011) was established to ensure collaborative working on sport policy between all levels of government and NSOs, overseen by the Meeting of Sports and Recreation Ministers (part of the Council of Australian Governments (COAG)). Despite the existence of these formal arrangements, coordination among federal and state-based targetsetting initiatives or between the upper two tiers of government and local government is not evident. In Sport 2030 local government is mentioned as part of the 'sport ecosystem' and as one of the sectors to be partnered with (Australian Government 2018, 10,19) and there is a reference to facilities, or 'infrastructure', with a commitment to 'examine a more collaborative model of sports infrastructure funding' and to 'develop a national approach to mapping infrastructure across Australia' (pp. 28, 29). However, at present, no active strategy for the provision of facilities to accommodate the targeted $15 \%$ increase in demand/ participation is apparent. It might be argued that this would stretch the scope of the national government too far. However, there are precedents for government sponsorship of nationwide facility plans, as seen in France in the 1970s (Michel, 1996) and in the UK in the 1970s and 1980s (Sports Council, 1971; 1983). Such plans do not typically involve national governments themselves planning at the local level, but coordinating national, regional (state) and local planning systems so that they are compatible and mutually supportive and linked with related grant aid programs.

\section{Implications of the participation-based approach for local sport/recreation planning}

In light of the above discussion, the logical approach to progressing policy and planning for sport/recreation participation in Australia would be, as a first step, for the Meeting of Sports and Recreation Ministers, in the context of the NSARPF, to determine the implications of the Sport 2030 participation targets for each state/territory ${ }^{3}$. State/territory governments could then consider the implications for local council planning in their respective areas. The relevance of box 6a in Figure 2 now becomes clear: state and territory governments, through their own policies and the collective efforts of the local councils in their respective areas, would stand alongside the direct action of Sport Australia and the activities of NSOs as part of the national planning/ policy framework. A version of Figure 2 could then be adopted in each state and territory, with 'state/territory community' replacing 'national community', the state/territory sport/ recreation commission replacing 'Sport Australia' and 'local government' replacing 'states/territories' in box 6a. Coordinating the planning activity of three levels of government would, no doubt, be challenging. However, this type of challenge, at least at the federal and state levels, is faced in a number of other policy sectors in Australia, notably health and education. It involves a process known as cooperative federalism (Wanna, Phillimore, Fenna and Harwood, 2009).

\footnotetext{
${ }^{3}$ The AusPlay survey provides participation data at state/territory level.
} 
Whether or not the above inter-level coordination takes place, there is a case for local councils to adopt the participation-based approach. It would, after all, be strange if local plans for recreation were completely oblivious to nation-wide and/or state/territory plans for the same phenomenon. Figure 3 indicates how the local planning model of Figure 1 could be modified to become a participation-based model.

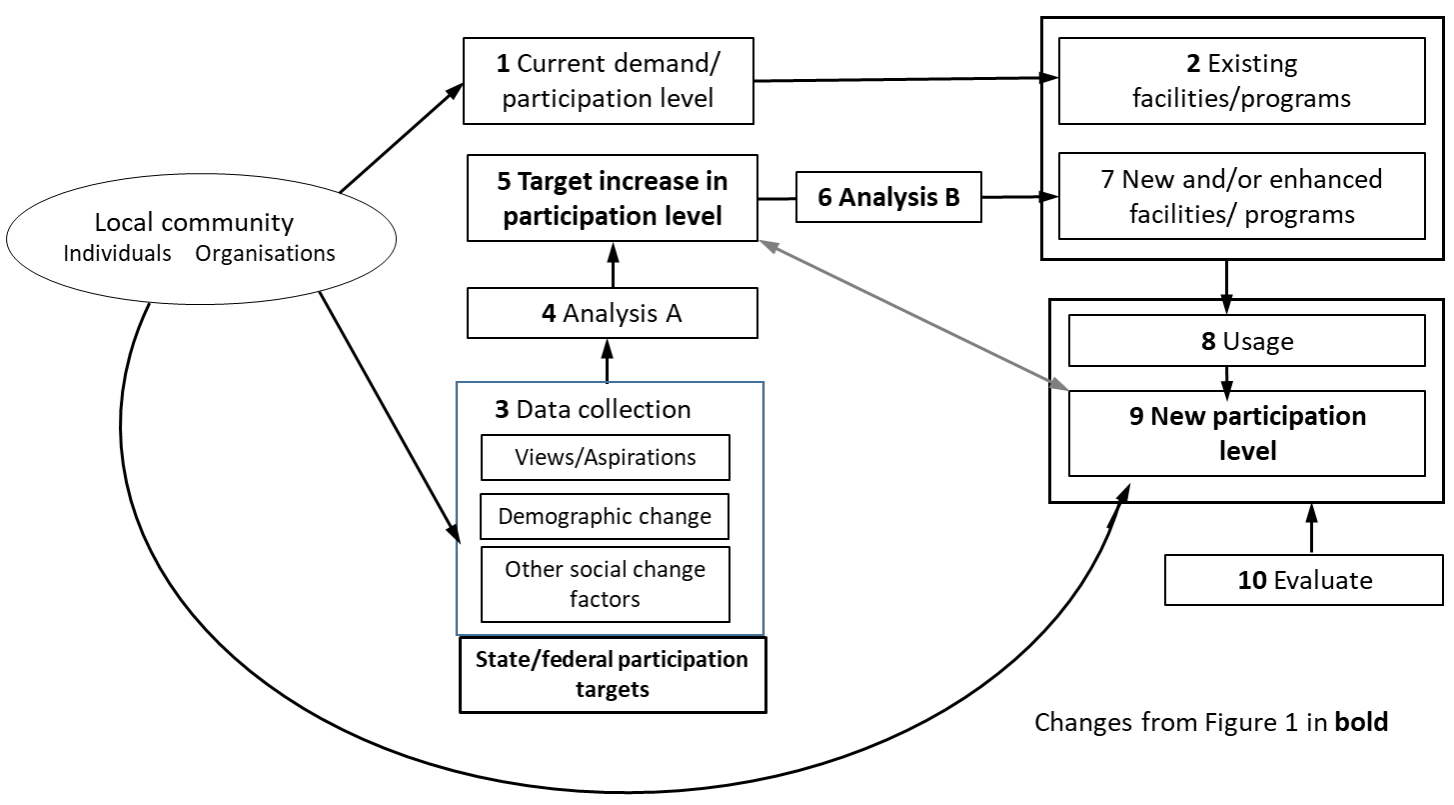

Figure 3 Participation-based local planning model

As with Figure 1, the status quo is represented by current demand/participation (1) taking place in existing facilities (2). Much of the data collection (3) undertaken for the demandbased model would still take place but, in addition, state/federal target participation targets and health-related physical activity guidelines would be taken into account. This might result from: a coordinated process as discussed above; a council's independent decision to align its targets with national/state targets; or a council taking an independent view on the state of its community's physical activity levels and health status. Analysis A (4) would convert this into a target increase in participation level for the community (5). Analysis B (6) is an additional task which would consider the activities and the quantum of facilities of various types which would best accommodate the target increase in demand. The success of the exercise is evaluated (10) by comparing the new facility usage (8) and participation level (9) in relation to the targeted increase. Remedying any shortfall in participation becomes, at least initially, a matter for facility management.

A number of implications flow from the adoption of a participation-based approach at local level.

- Surveys. Levels of participation/demand need to be measured at the beginning of the process and at the end. If local, state/territory and national recreation participation rates are to have some sort of relationship, then the definitions and methodology used for measuring participation would need to be aligned. The national AusPlay survey already provides data at state/territory level (Sport Australia bi-annual), but not at individual council level. The implication is that local demand/participation surveys should use the 
same methodology as AusPlay ${ }^{4}$. In England, this national/local link is facilitated by the equivalent of AusPlay, the Active Lives Survey, being funded by Sport England (from the National Lottery) with a sample large enough to provide data at individual local council level (Sport England 2019).

- Measurement. At local level, there is a direct connection between demand/participation and facilities. If a certain level of demand/participation for an activity is planned to be accommodated in a given facility, the capacity of the facility and the quantum of demand/ participation must both be expressed using a common unit of measurement - for example visits per week. This may therefore involve translation of a national or state "number of active individuals' into a volume measure. For example, with an average frequency of participation of two times a week, Sport Australia's targeted annual increase of 200,000 in the number of active individuals, as noted above, would represent 400,000 visits per week.

- New release areas. The participation-based approach goes some way to solving the problem raised in the Tasmanian and the NSW 1992 guidelines, namely planning in new release areas, which contain no resident population when the planning exercise is being undertaken. The overall target level of demand/participation being planned for in the host council area $((1)+(5)$ in Figure 3$)$, expressed as a level of activity per 1000 population, is also the activity rate to be provided for in the new release area. This might be modified by socio-demographic characteristics of the planned population to the extent that this is known. This approach also overcomes the problem of developers objecting to new areas being 'gold-plated', since the level of activity being planned for in the new area is the same as that being planned for in the community as a whole.

- Density. The approach also addresses the density issue discussed at the beginning of this article. The range of outdoor facilities typically provided in low density areas cannot be provided in high density areas due primarily to cost. However, it is arguable that residents of these areas have the right to participate in a level of physical recreation activity similar to that of the rest of the community, particularly if part of the rationale behind the policy is people's health. The community-wide target demand/participation rate, as with new release areas, is also applicable to high density areas. The planning task (step 6 in Figure 3 ) is to assemble a range of facilities which will accommodate the required volume of activity but in a smaller land area than the traditional mix of facilities typically provided in low-density areas. In particular, hard surface and indoor facilities, open for long hours for seven days a week, can accommodate multiples of much larger outdoor grass-surfaced facilities.

The above discussion does not, of course, constitute a complete guide to the implementation of a participation-based planning approach. While a more detailed outline of a generic academic version of such a model exists ${ }^{5}$, a step-by-step guide would be required for Australian use. It would need to address at least such matters as: approaches to the setting of local participation targets, in association with federal/state health-related targets and/or independently; the process of translating demand/participation targets into requirements for types of facility; the conduct, analysis and scope of local demand/participation surveys and their relationships with national and state/territory surveys; integration into the model of existing local social policy priorities and expressed demand/aspirational data; consideration

\footnotetext{
${ }^{4}$ A further issue for consideration is the extent to which AusPlay aligns with the findings on physical activity levels in the Australian Health Survey (Australian Institute of Health and Welfare 2018).

${ }^{5}$ See Veal (2017): Chapter 9, 'A participation-based approach to planning for leisure, sport and tourism', pp. 176-202.
} 
of requirements for children's demand/participation; and, where applicable, treatment of visiting tourist and worker demand/participation.

This article is not a detailed blue-print for change; it offers some observations on the status quo, some suggestions for change and an invitation to debate.

\section{References}

Australian Government 2018. Sport 2030: Participation, performance, integrity, industry. Canberra: Commonwealth of Australia/Department of Health.

Australian Government 2019. Australian Sports Commission: Entity resources and planned performance (Portfolio Budget Statement). Canberra: Australian Government. (at: www.sportaus.gov.au/_data/assets/pdf_file/0008/711962/201920_Health_PBS_4.07_ASC.pdf).

Australian Governments 2011. National Sport and Active Recreation Policy Framework. Canberra: Commonwealth of Australia.

Australian Institute of Health and Welfare (AIHW) 2018. Physical Activity Across the Life Stages. Canberra: AIHW.

Australian National Audit Office 2018. Corporate Planning and Performance Statements Under the PGPA Act. Canberra: ANAO, at: www.anao.gov.au/work/audit-insights/corporate-planning-andperformance-statements-under-pgpa-act\#7-0-performancestatements.

Australian Social and Recreation Research Pty Ltd (ASR) 2008. Planning for Community Infrastructure in Growth Areas. Report to a consortium of five Victorian growth area councils: www.wyndham.vic.gov.au/aboutwyndham/planspolicieslocallaws/commdev/plancominfr.

Australian Sports Commission 2002. Strategic Plan: 2002-2005. Canberra: ASC.

Australian Sports Commission 2006. Strategic Plan: 2006-2009. Canberra: ASC.

Sport Australia 2019. Corporate Plan: 2019-23. Canberra: Sport Australia.

Brown, A.J., and Sherrard, H.M. 1951. Town and Country Planning. Melbourne: Melbourne University Press.

Byrne, J., and Sipe, N., 2010. Green and Open Space Planning for Urban Consolidation: A review of the literature and best practice. Issues Paper 11, Brisbane: Griffith University Urban Research Program.

Commonwealth of Australia, Department of Health, Housing and Community Services 1995. AMCORD: Australian Model Code for Residential Development: A National resource document for residential development. Canberra: AGPS.

Department for Culture, Media and Sport 2008 Playing to Win: A new era for sport. London: DCMS. Gold, S.M. 1980. Recreation Planning and Design. New York: McGraw-Hill.

Gray, J. E., and Cullen, P. 1976. Guidelines for the Management of Urban Park Systems. Northcote, Vic: Royal Australian Institute of Parks and Recreation.

Houlihan, B. 2011. England. In Nicholson, M., Hoye, R., \& Houlihan, B. (Eds), Participation in Sport: International policy perspectives (pp. 10-24). London: Routledge.

Jeavons, S. 2000. Whose fault is it anyway? Australian Leisure Management, 18, 42-44.

Jones, S. 2018. Will the government's new 'Move It' exercise campaign move us or lose us? The Conversation, 7 Aug, 2018, https://theconversation.com/will-the-governments-new-move-itexercise-campaign-move-us-or-lose-us-100969.

Marriott, K. 1980a. Traditional approaches to urban recreation planning. In D. Mercer and E. Hamilton-Smith (Eds), Recreation Planning and Social Change. Malvern, Vic.: Sorrett, pp. 11323.

Marriott, K. 1980b. Urban recreation open space and facility planning. In D. Mercer and E. HamiltonSmith (Eds), Recreation Planning and Social Change. Malvern, Vic.: Sorrett, pp. 132-52.

Michel, A. 1996. Sports policy in France. In L. Chalip, A. Johnson and L. Stachura (Eds), National Sports Policies: An international handbook (pp. 139-60). Westport, CN: Greenwood Press.

NSW Department of Environment and Planning 1984. Guidelines for Preparing an Open Space Plan. Sydney: D.E.P. 
NSW Department of Planning 1992. Outdoor Recreation and Open Space: Planning guidelines for local councils. Sydney: Department of Planning.

NSW Department of Planning 2010. Recreation and Open Space Planning Guidelines for Local Government. Prepared by SGS Economics and Planning. Sydney: NSW Department of Planning.

NSW Government 2010. NSW 2021: A plan to make NSW number one. Sydney: NSW Government. Meller, H.E. 1976. Leisure and the Changing City, 1870-1914. London: Routlegde and Kegan Paul.

NSW Office for Sport 2017. Strategic Plan: 2018-2022. Sydney: Office for Sport.

Parks and Leisure Australia, Victoria 2013. Open Space Planning and Design Guide. Melbourne: Parks and Leisure Australia, Victoria.

Parks and Leisure Australia, WA 2012. Guidelines for Community Infrastructure. Perth: Parks and Leisure Australia, WA.

Productivity Commission 2009. Strengthening Evidence-based Policy in the Australian Federation, 2 Vols. Canberra: Productivity Commission.

South Australian Government 2007. Strategic Plan 2007. Adelaide: SA Government.

South Australian Government 2016. SA Strategic Plan: Target 83: Sport and Recreation. Adelaide:

SA Department of Planning, Transport and Infrastructure, https://data.sa.gov. au/ data/dataset/sasp-target-83-sport-and-recreation.

Sport and Recreation Tasmania 2010. Planning for the Provision of Leisure and Recreation in Australia. Prepared by K. Marriott. Hobart: Sport \& Recreation Tasmania.

Sport Australia 2019. Corporate Plan: 2019-23. Canberra: Sport Australia.

Sport Australia (bi-annual). AusPlay results. Canberra: Australian Sports Commission, on-line at: www.clearinghouseforsport.gov.au/research/smi/ausplay.

Sport England 2019. Active Lives Adult Survey: May 18/19 report. London: Sport England.

Sports Council 1971. Sport in the Seventies: making good the deficiencies. The need for a planned programme of capital investment in sports facilities. London: Sports Council.

Sports Council 1983. A Forward Look: Rolling programme 1983-88. London: Sports Council.

State of Victoria 2017. Active Victoria: A strategic framework for sport and recreation in Victoria 2017-2021. Melbourne: Department of Health and Human Services, Victorian Government.

Taylor, P. (Ed.) 2010. Torkildsen's Sport and Leisure Management, $6^{\text {th }}$ Edn. London: Routledge.

Veal, A.J. 2013. Open space planning standards in Australia: in search of origins. Australian Planner, 50(3), 224-32.

Veal, A.J. 2017. Leisure, Sport and Tourism: Politics Policy and Planning, $4^{\text {th }}$ Edn. Wallingford, UK: CABI.

Veal, A.J., Darcy, S., and Lynch, R. 2013. Australian Leisure (4th edn.). Frenchs Forest, NSW: Pearson.

Victorian Growth Areas Authority 2009. Precinct Structure Planning Guidelines, 2 Vols. Melbourne: GAA.

WA Department of Sport and Recreation 2007. Decision-making Guide: Sport and recreation facilities. Perth: Western Australia Department of Sport and Recreation.

Wanna, J., Phillimore, J., Fenna, A., and Harwood, J. 2009. Common Cause: Strengthening Australia's cooperative federalism. Canberra: Council for the Australian Federation.

World Health Organization (2010). Global recommendations on physical activity for health. Geneva: WHO. 